\title{
Authorship problems in scientific literature and in nuclear medicine: the point of view of the young researcher
}

\author{
Salvatore Annunziata • Alessandro Giordano
}

Published online: 26 March 2014

(C) Springer-Verlag Berlin Heidelberg 2014

\section{Introduction}

In recent years, different ethical problems have emerged in the scientific literature $[1,2]$. Disputes can occur when including or excluding authors' names in scientific papers that, nowadays, are frequently multiauthor articles. These problems, called "authorship" problems, are prompted by the competitive scientific climate and by the increasing use of bibliometric indices to measure the academic performance of individual researchers [3]. In the last 30 years, many groups, editors and scientific committees have debated the authorship problem, including the International Committee of Medical Journal Editors (ICMJE), the European Association of Science Editors (EASE), the Committee of Publication Ethics (COPE) and the Office of Research Integrity (ORI, in the USA). Our aim was to investigate the emerging importance of authorship problems in scientific literature, with particular regard to the role of young researchers and to the field of nuclear medicine.

\section{The interest of young researchers in "gift" and "ghost" authorship}

The most recognized guidelines for authorship, edited by the ICMJE [4], followed by approximately 500 medical journals, define an author as someone who: (1) has made significant contributions to the conception and design, or to the acquisition of data, or to the analysis and interpretation of data, (2) has been involved in drafting the article or revising it critically for important intellectual content, and (3) has provided final approval of the version to be published. The guidelines say

S. Annunziata $(\bowtie) \cdot$ A. Giordano

Institute of Nuclear Medicine, Università Cattolica del Sacro Cuore, Largo Agostino Gemelli 8, 00168 Rome, Italy

e-mail: salvatoreannunziata@live.it that all three criteria must be met for authorship. Furthermore, each author should have sufficiently participated in the study to take public responsibility for appropriate portions of the content. Acquisition of funding, data collection or supervision alone do not qualify for authorship [4].

Gift authorship refers to people who are listed as authors but who did not make a significant contribution to the research [5]. These are frequently senior figures who often expect to have their name included among the authors regardless of their real contribution to the study; this practice is often referred to as "honorary" authorship. Gift authorship is indicated when the authors include in the paper's list of authors the name of a colleague who did not contribute to the research, expecting that the individual will do the same for them in the future. When this practice is engaged in by several researchers, a publication cartel is formed, and this can be considered a most dishonest way to repeatedly multiply the number of publications of each researcher [3]. Honorary and gift authorship can be either voluntary or coerced. The latter often applies to young researchers who are repeatedly asked to insert the name of senior colleagues in the their paper's list of authors [6]; this practice has been called "publication parasitism" [7]. Several articles in the literature report attempts to measure the frequency of papers affected by honorary and gift authorship. According to Flanagin et al. [8], the frequency is about $20-25 \%$, and according to Bates [9]. the frequency varies between $4 \%$ and $60 \%$, depending on the journal. We strongly agree with the recent editorial by Greenland and Fontanarosa who hope that honorary and gift authorship will end, condemning it as a highly unethical practice [10].

A ghost author could be a professional writer, often paid by sponsors, excluded from the list of authors due to a conflict of interest. More frequently, ghost authors are those who meet international criteria for authorship, but are excluded from the article's list of authors. They are frequently trainees or young researchers. Albert and Wager wrote a guide aimed at helping 
young researchers to become involved in this practice [5]. They made several suggestions, even inviting junior researchers to make sure that their departmental library has at least one book on publication ethics! There is no doubt that senior researchers, and the head of the research department or institute, when not involved in these dishonest practices, should accept the responsibility to guarantee that the contributions by young researchers are recognized. However the role of senior figures in research teams is also debated. According to Albert and Wager, one author should act as research "guarantor" to preserve and warrant the integrity of the whole work [5] and this individual should be included in the list of authors. On the other hand, this definition could be in conflict with authorship criteria, which do not clearly define this role and could even consider the guarantor as a guest author. The ICMJE criteria for authorship seem not to consider that this role may be played by one of those entitled to be included as an author. Until now, no clear indications have been proposed for the role of guarantor in scientific papers. We believe that this role needs to be better defined. Editors themselves need to have an author who represents the research team in case of controversy.

Other frequent authorship problems are those concerning the order of authors, the choice of a corresponding author, and editing the copyright assignment forms. In these cases, before involving journal editors, the authors raising the problem should first consult a senior member of their team. In some cases, the head of department/institute, or even the dean of the faculty, could become involved, to clarify specific problems within the research team. Sometimes the problems can reach the journal's editors in chief. Withdrawal, removal or replacement of a published paper are the last steps taken by journal editors if authors have failed to comply with international guidelines for authorship [11, 12], although editors often have few elements to evaluate and solve disputes among authors. In many cases the communication of the complaint to the author or to the authors' institution could itself be considered a significant sanction. Other "remedies" may include publication of a notice, corrigendum or erratum in a future issue, formal retraction of the article, formal removal of the article, or publication of an editorial concerning the ethical issues. A better knowledge of such remedies by the scientific community may prevent or limit disputes and misconduct in the field of authorship [12], especially in protecting the interests of young researchers.

\section{Practical advice: what to do in the real world}

Useful information and advice can be obtained from the European Association of Science Editors (EASE) or from the Committee of Publication Ethics (COPE) who have also published a "guide for new researchers" [5]. The website of the ORI (http://ori.hhs.gov/) provides useful data and suggestions on how to handle authorship problems according to international guidelines.

Many problems can be avoided, starting by discussing authorship at the time of research planning, deciding on authorship before starting the study and encouraging "ethical authorship" [5]. "If scientists are dishonest about their participation in the study, this undermines confidence in reporting the work itself" - this is the key concept of the Uniform Requirements for Manuscripts by ICJME [4]. An ethical scientific research paper cannot allow unethical conduct concerning authorship.

To limit these regrettable problems and to preserve the rights of young scientists, the Quantitative Uniform Authorship Declaration System (QUAD) has been proposed [13] (Table 1). This system is now recommended by many editors and allows the contribution of each author to be quantified in all parts of the scientific study, such as concept, design, data collection, analysis, conclusion and writing. A minimum contribution by all authors to each category is required [13]. It is self-evident that it is not easy to quantify each contribution, but the attempt to do so underlines the principle of "sufficient participation" in the work.

In Germany, the "Ombudsman für die Wissenschaft" is a committee that deals with all questions regarding good research practice; its mission is to support researchers, to prevent malpractice and to help in solving controversies between individuals or institutions with regard to scientific honesty. Unfortunately, elsewhere in Europe, an ombudsman system is
Table 1 Example of the use of the QUAD system concerning the article "A prospective analysis of ${ }^{18} \mathrm{~F}$-FDG PET/CT in patients with uveal melanoma: comparison between metabolic rate of glucose (MRglu) and standardized uptake value (SUV) and correlations with histopathological features" by Calcagni ML, Mattoli MV, Blasi MA, Petrone G, Sammarco MG, Indovina L, Mulè A, Rufini V, Giordano A. Eur J Nucl Med Mol Imaging. 2013;40(11):1682-91

\begin{tabular}{|c|c|c|c|c|c|c|c|c|c|c|}
\hline & Calcagni & Mattoli & Blasi & Petrone & Sammarco & Indovina & Mulè & Rufini & Giordano & Total \\
\hline Concept/design & $50 \%$ & - & $30 \%$ & - & - & - & $10 \%$ & - & $10 \%$ & $100 \%$ \\
\hline Data collection & - & $70 \%$ & - & $10 \%$ & $10 \%$ & $10 \%$ & - & - & - & $100 \%$ \\
\hline Analysis/conclusion & $50 \%$ & $10 \%$ & $10 \%$ & - & - & $10 \%$ & - & $10 \%$ & $10 \%$ & $100 \%$ \\
\hline Writing & $40 \%$ & $30 \%$ & - & $10 \%$ & $10 \%$ & - & - & $10 \%$ & - & $100 \%$ \\
\hline
\end{tabular}


not as common as in the USA, where universities such as Columbia and Northern Illinois even have their own institutional guidelines for responsible authorship (http://ori.hhs. gov/). The ORI suggests that young researchers should know the policy of their laboratory, department or institution with respect to what constitutes an author and should try to discuss authorship in advance with colleagues and supervisors (http://ori.hhs.gov/).

The authors of this paper are the director (A.G.) and a resident (S.A.), respectively, of an academic department of nuclear medicine devoted to teaching and research within a large teaching hospital. About 15 researchers of different ages and responsibilities are employed in the department, together with about 15 young residents. The research activities of the department are coordinated by a committee ('Consiglio di Istituto') whose members are the director, most of the senior researchers and representatives of the residents; the committee holds meetings on a monthly basis. In order to govern research matters, to avoid the development of authorship disputes, and to guarantee the rights of young residents, the committee believes that relying only on the principles of research ethics might not suffice. Instead the committee considers that the key to avoiding disputes is to demand maximum transparency in every research step, from the origin (research project) to the end (forwarding the manuscript). Authorship disputes should be prevented if all members of the department are made aware of every ongoing research project, and of the names of the authors as provided by the researchers themselves. The committee believes that research has to remain free; it is not acceptable for researchers to be controlled or oriented in either the research topic or the choice of the coworkers. The committee has established the following rules concerning authorship:

1. Every manuscript written by one or more members of the department has to have a responsible author who is indicated by the authors themselves; the responsible author is a member of the department; residents cannot be responsible authors unless they are in the last year of residency.

2. Before being sent to the editor of a journal, the responsible author must provide every manuscript to the committee. The committee does not evaluate the quality of the text, the data reported, or the authorship list except if specifically requested by any member of the department (the transparency of the procedure towards all members of the committee is considered a sufficient guarantee to avoid malpractice). The manuscripts are freely available to any member of the department in the secretary's office.

3. Every month the committee organizes a scientific meeting involving all department members; each meeting is devoted to a specific research field (i.e. nuclear cardiology, nuclear neurology, etc.). All department members are encouraged to report on the research they are working on, the manuscripts sent and eventually published, and future research projects. The names of the authors involved are presented to the committee (this should avoid possible future authorship disputes). Every research topic is discussed at least once a year.

4. If a manuscript is published in a journal without disclosure to the committee, the director of the department, on behalf of the Committee, has the right to request that the editor retract the paper or retract the affiliation of the authors, in order to guarantee the reputation of the department.

5. The rules of ICJME are approved by the committee and are included in the rules of the department.

The committee has not yet reached a final decision concerning the role of guarantor of the research, a controversial role in the literature that might overlap with honorary authorship and/or with our role of responsible author. These rules are effective as of May 2013; until now the role of responsible author has been attributed to the last author in the list of authors. The director of the department is the responsible author only when he significantly contributed to the research (according to ICJME principles); in other cases the responsible author has always been the most senior author.

\section{Authorship problems in nuclear medicine: the role of young researchers}

Nuclear medicine researchers as well as radiologists have the same risk of becoming involved in authorship problems as other colleagues. Indeed, the frequent collaboration with colleagues from other departments who have the responsibility for patient care exposes nuclear medicine researchers and radiologists, at least theoretically, to an even higher risk of authorship disputes due to such close interspecialty collaboration, resulting in an increased number of contributors. "Poliauthoritis" [14] is a publication disease that increases the risk of authorship problems. Nevertheless, no known case has emerged in the literature, and no paper focusing on authorship problems in nuclear medicine has been published, in particular with regard to young researchers.

In our opinion, in nuclear medicine as in all medical branches, the appropriate use of authorship establishes accountability, responsibility and credit for the scientific information in biomedical publications [8]. We strongly believe that there is a need for a discussion in academic circles on a way to reduce the emphasis on productivity and the number of publications. In this way, many authorship problems could be avoided, and the rights of young researchers could be preserved. Quality in scientific research should be preferred to the quantity of publications; this may include using different systems for the evaluation of publications. Using the $\mathrm{H}-$ 
index instead of the Impact Factor could be a first step in the right direction; the second step might be the need to display the nature of the contribution and the specific size of the contribution by each author in every multiauthor scientific paper. Finally, in Europe as well as in the USA, national "ORI-like" institutions should be more widely established to monitor the results of scientific research. Also there should be more ombudsman systems in research institutions or within local ethics committees; they could be a great help, especially in protecting the interests of young scientists.

Acknowledgments The authors thanks Prof. W.H. Knapp of the International Neuroscience Institute, Hanover, Germany, for his help in describing the role of "Ombudsman für die Wissenschaft" in Germany.

\section{Conflicts of interest None.}

\section{References}

1. Godlee F, Jefferson T. Peer review in health sciences. London: BMJ Books; 1999.

2. Hudson Jones A, McLellan F. Ethical issues in biomedical publication. Baltimore: The Johns Hopkins University Press; 2000.

3. Kovacs J. Honorary authorship epidemic in scholarly publications? How the current use of citation-based evaluative metrics make (pseudo)honorary authors from honest contributors of every multiauthor article. J Med Ethics. 2013;39(8):509-12.

4. International Committee of Medical Journal Editors. Uniform requirements for manuscripts submitted to biomedical journals: ethical considerations in the conduct and reporting of research: authorship and contributorship.http://www.icmje.org/recommendations/ archives/2004_urm.pdf. Accessed 14 Mar 2014.

5. Albert T, Wager E. The COPE Report 2003. How to handle authorship disputes: a guide for new researchers. http://publicationethics. org/files/2003pdf12.pdf. Accessed 14 Mar 2014.

6. Wagena EJ. The scandal of unfair behaviour of senior faculty. J Med Ethics. 2005;31:308.

7. Kwok L. The White Bull effect: abusive coauthorship and publication parasitism. J Med Ethics. 2005;31(9):554-6.

8. Flanagin A, Carey LA, Fontanarosa PB, Phillips SG, Pace BP, Lundberg GD, et al. Prevalence of articles with honorary authors and ghost authors in peer-reviewed medical journals. JAMA. 1998;280(3):222-4.

9. Bates T, Anić A, Marusić M, Marusić A. Authorship criteria and disclosure of contributions: comparison of 3 general medical journals with different author contribution forms. JAMA. 2004;292(1):86-8.

10. Greenland P, Fontanarosa PB. Ending honorary authorship. Science. 2012;337(6098):1019.

11. Wager E. Recognition, reward and responsibility: why the authorship of scientific papers matters. Maturitas. 2009;62(2):109-12.

12. Elsevier. Publishing Ethics Resource Kit. http://www.elsevier.com/ editors/perk. Accessed 14 Mar 2014.

13. Verhagen JV, Wallace KJ, Collins SC, Scott TR. QUAD system offers fair shares to all authors. Nature. 2003;426(6967):602.

14. Borry P, Schotsman P, Dierickx K. Author, contributor or just a signer? A quantitative analysis of authorship trends in the field of bioethics. Bioethics. 2006;20:213-20. 